Background: B-lymphocyte stimulator (BLyS) is increased in primary Sjögren's syndrome (pSS) and plays a role in the B-cell hyperactivity thought to contribute to pSS. Belimumab (BEL, anti-BLyS) and rituximab (RTX, anti-CD20) target B cells through distinct and potentially complementary mechanisms.

Objectives: To evaluate the safety and efficacy of subcutaneous (SC) BEL/intravenous (IV) RTX combination (BEL/RTX) in patients with pSS.

Methods: This Phase 2, double-blind study (GSK Study 201842; NCT02631538) randomised 86 adults with active pSS to 4 treatment arms stratified for baseline EULAR Sjögren's Syndrome Disease Activity Index (ESSDAI) scores 5-12 or >12: placebo (PBO; $N=13)$, BEL/RTX ( $N=24$; BEL $200 \mathrm{mg} \mathrm{SC}$ weekly to Week [Wk] 24 followed by weekly PBO SC to Wk 52 + RTX 1000 mg IV, Wk 8+10), BEL monotherapy ( $\mathrm{N}=24$; BEL $200 \mathrm{mg}$ SC weekly to Wk 52) or RTX monotherapy $(\mathrm{N}=25 ; \mathrm{RTX} 1000 \mathrm{mg}$ IV, Wk $8+10)$. Follow-up was at Wk 68 . Safety to Wk 68 was the primary endpoint (safety population; patients received $\geq 1$ dose of study treatment). Secondary/other endpoints (completer population; patients completed treatment and follow-up phase) were ESSDAI score, stimulated salivary flow, CD20+ B-cell count within salivary gland biopsies, patient-reported oral dryness, and EULAR Sjögren's Syndrome Patient Reported Index (ESSPRI) score.

Results: Baseline demographics and disease characteristics were similar among arms. Adverse events (AEs) were balanced across arms. Serious AEs were infrequent but occurred only in active treatment arms (Table). No unexpected safety issues were identified with BEL/RTX relative to BEL or RTX. Treatment phase and follow-up were completed by $60 / 86$ patients. ESSDAI reductions with BEL/ RTX were numerically greater over time than $\mathrm{PBO}$, with greatest difference at Wk 68 (Table), but were not differentiated from monotherapy. Stimulated salivary flow showed a trend favouring BEL/RTX vs PBO over later time points (Table). In contrast with PBO, BEL, and RTX, salivary gland biopsies from BEL/RTX showed almost complete B-cell depletion (Wk 24). There was no clear evidence for a positive effect of BEL/RTX on patient-reported oral dryness or ESSPRI score.

Table 1. Key safety endpoints and selected efficacy endpoints

\begin{tabular}{lcccc}
\hline AEs - safety population & $\begin{array}{c}\text { PBO } \\
\mathbf{( N = 1 3 )}\end{array}$ & $\begin{array}{c}\text { BEL/RTX } \\
\mathbf{( N = 2 4 )}\end{array}$ & $\begin{array}{c}\text { BEL } \\
(\mathbf{N}=\mathbf{2 4})\end{array}$ & $\begin{array}{c}\text { RTX } \\
(\mathbf{N}=\mathbf{2 5})\end{array}$ \\
\hline AEs, n (\%) & $13(100)$ & $24(100)$ & $23(96)$ & $24(96)$ \\
Drug-related AEs, n (\%) & $10(77)$ & $17(71)$ & $16(67)$ & $14(56)$ \\
AEs leading to discontinuation/ & $1(8)$ & $5(21)$ & $3(13)$ & $5(20)$ \\
$\quad$ withdrawal, n (\%) & & & & \\
SAEs, n (\%) & 0 & $3(13)$ & $2(8)$ & $4(16)$ \\
Number of SAEs & 0 & 4 & 2 & 7 \\
Deaths, n (\%) & 0 & $1(4)^{\star}$ & 0 & 0 \\
Infections and Infestations, n (\%) & $11(85)$ & $19(79)$ & $21(88)$ & $18(72)$ \\
Efficacy - completer & $\mathbf{P B O}$ & $\mathbf{B E L} / \mathbf{R T X}$ & $\mathbf{B E L}$ & $\mathbf{R T X}$ \\
$\quad$ population & $\mathbf{( N = 8 )}$ & $\mathbf{( N = 1 7 )}$ & $\mathbf{( N = 1 9 )}$ & $\mathbf{( N = 1 6 )}$ \\
ESSDAl change, LS mean (SE) from $\mathrm{BL}$ over time & & & \\
Wk 12 & $-2.00(1.449)$ & $-4.85(0.996)$ & $-3.87(0.949)$ & $-4.22(1.048)^{\S}$ \\
Wk 24 & $-2.87(1.324)$ & $-5.32(0.911)$ & $-3.87(0.869)$ & $-5.25(0.940)$ \\
Wk 52 & $-2.87(1.294)$ & $-5.67(0.890)$ & $-4.76(0.850)$ & $-4.32(0.919)$ \\
Wk 68 & $-1.75(1.400)$ & $-5.73(0.962)$ & $-3.87(0.918)$ & $-4.38(0.994)$ \\
Stimulated salivary flow (ml/min), mean (SD) & & & \\
BL & $0.47(0.247)$ & $0.71(0.629)$ & $0.43(0.329)$ & $0.62(0.621)$ \\
Wk 12 & $0.49(0.205)$ & $0.75(0.834)$ & $0.49(0.373)$ & $0.58(0.527)$ \\
Wk 24 & $0.55(0.305)$ & $0.78(0.790)$ & $0.45(0.411)$ & $0.72(0.890)$ \\
Wk 52 & $0.53(0.378)$ & $1.00(1.146)$ & $0.58(0.608)$ & $0.69(0.781)$ \\
Wk 68 & $0.36(0.163)$ & $0.88(0.817)$ & $0.52(0.450)$ & $0.73(0.785)^{\S}$ \\
\end{tabular}

${ }^{*}$ Aspiration $(n=1)$; not considered related to treatment; patient died of food aspiration; ${ }^{\dagger}$ System organ class with the highest percent of AEs; ${ }^{\ddagger}$ Analysis was performed using mixed model repeated measures; ${ }^{\S} n=15 . B L$, baseline; LS, Least square; SAEs, serious AEs; SD, standard deviation; SE, standard error

Conclusion: No unexpected safety issues were identified with BEL/RTX relative to BEL or RTX. BEL/RTX showed a trend towards improvement in ESSDAI and stimulated salivary flow over time, which was sustained post treatment. BEL/RTX depleted B cells in minor salivary gland biopsies.

Funding: GSK

Acknowledgements: Medical writing assistance was provided by Katalin Bartus, PhD, Fishawack Indicia Ltd., UK, part of Fishawack Health, and was funded by GSK.

Disclosure of Interests: Xavier Mariette Consultant of: BMS, Galapagos, Gilead, GSK, Janssen, Novartis, Pfizer, Servier, UCB, Grant/research support from: Servier, Chiara Baldini: None declared, Francesca Barone Consultant of: GSK, UCB, Roche, Actelion, Grant/research support from: GSK, UCB, Roche, Actelion, Employee of: Kintai therapeutics, Candel Therapeutics, Hendrika Bootsma Speakers bureau: BMS, Novartis, Consultant of: BMS, Roche, Novartis, Medlmmune, UCB, Servier, Grant/research support from: BMS, Roche, Ken Clark Shareholder of: GSK, Employee of: GSK, Salvatore De Vita Consultant of: GSK, Roche, Karoline Lerang: None declared, Prafull Mistry Shareholder of: GSK, Employee of: GSK, Frederic Morin: None declared, Rajesh Punwaney Shareholder of: GSK, Employee of: GSK, Raphaèle Seror Consultant of: GSK, BMS, Fresenius Kabi, Boehringer, Jansen, Amgen, Pfizer, Roche, Paul LA van
Daele: None declared, Andre van Maurik Shareholder of: GSK, Employee of: GSK, Nicolas Wisniacki Shareholder of: GSK, Employee of: GSK, David Roth Shareholder of: GSK, Employee of: GSK

DOI: 10.1136/annrheumdis-2021-eular.2170

\section{OP0136 RITUXIMAB PREVENTS THE PROGRESSION OF B-CELL DRIVEN INFLAMMATORY INFILTRATE IN THE MINOR SALIVARY GLANDS OF PRIMARY SJOGREN'S SYNDROME BY DOWNREGULATING IMMUNOLOGICAL PATHWAYS KEY IN ECTOPIC GERMINAL CENTRE ORGANIZATION: RESULTS FROM THE TRACTISS TRIAL}

E. Pontarini ${ }^{1}$, F. Chowdhury ${ }^{1,2}$, E. Sciacca ${ }^{1}$, S. Grigoriadou ${ }^{1}$, F. Rivellese ${ }^{1}$, D. Lucchesi ${ }^{1}$, K. Goldmann ${ }^{1}$, L. Fossati-Jimack ${ }^{1}$, P. Emery ${ }^{3}$, W. F. Ng ${ }^{4}$, N. Sutcliffe ${ }^{5}$, C. Everett ${ }^{6}$, C. Fernandez ${ }^{6}$, A. Tappuni ${ }^{2,5}$, M. Lewis $^{1}$, C. Pitzalis ${ }^{1}$, S. J. Bowman ${ }^{7}$, M. Bombardieri ${ }^{1}{ }^{1}$ William Harvey Research Institute, Queen Mary University of London, Experimental Medicine and Rheumatology, London, United Kingdom; ${ }^{2}$ Institute of Dentistry, Queen Mary University of London, Oral Immunobiology and Regenerative Medicine, London, United Kingdom; ${ }^{3}$ Leeds Institute of Rheumatic and Musculoskeletal Medicine, University of Leeds, Chapel Allerton Hospital, Leeds, United Kingdom; ${ }^{4}$ Translational and Clinical Research Institute, Newcastle University, Newcastle-upon-Tyne, Newcastle, United Kingdom; ${ }^{5}$ Royal London Hospital, Bart's Health NHS Trust, Rheumatology department, London, United Kingdom; ${ }^{6}$ Leeds Institute for Clinical Trials Research, University of Leeds, Clinical Trials Research Unit, Leeds, United Kingdom; ${ }^{7}$ University Hospitals Birmingham NHS Foundation Trust, Rheumatology Department, Birmingham, United Kingdom

Background: The pathogenic role of B-cells in primary Sjögren's Syndrome (pSS) is well established and B cell abnormalities. Because of the substantial role of B-cells, rituximab (RTX), a chimeric anti-CD20 monoclonal antibody, has been considered as a potential biologic disease modifying drug to reduce disease activity in pSS. To date, the TRial for Anti-B-Cell Therapy In patients with pSS (TRACTISS) is the largest multi-centre, placebo-controlled trial with RTX. Despite the unmet primary endpoints (30\% reduction in fatigue or oral dryness, measured by visual analogue scale), RTX treated patients showed an improvement in unstimulated whole salivary flow (Bowman et al. Arthritis Rheumatol 2017;69:1440-1450)

Objectives: To provide the first longitudinal transcriptomic and histological analysis at 3 time points over 48 weeks of labial SGs of pSS patients treated with RTX in comparison to placebo, from the TRACTISS cohort.

Methods: 26 pSS patients randomised to RTX or placebo arm consented for labial SG biopsies at baseline, weeks 16 and 48. Patients received two 1000mg cycles of RTX or placebo at baseline and week 24. SG focus score, inflammatory aggregate area fraction, B-cells (CD20+), T-cells (CD3+), follicular dendritic cells (FDCs) (CD21+) and plasma cells (CD138+) density were assessed by H\&E and immunofluorescence staining. The histological analysis was performed by digital imaging using QuPath software. RNA was extracted from matched labial SG lobules and sequenced with Illumina platform. A Principal Component Analysis (PCA) and features driving the PCA were investigated along with the most influential gene loadings. The limma-voom $\mathrm{R}$ pipeline was used to extract Differential Expressed Genes (DEGs) between placebo and RTX group at week 48, and gene ontology (GO) enrichment analysis performed through EnrichR to derive GO terms and pathways associated with DEGs.

Results: Placebo-treated labial SGs showed a worsening of inflammation highlighted by the increment of B-cell density, development of new FDC networks, and a higher ectopic GC prevalence at week 48, compared to RTX-treated patients. No difference in total T-cells and plasma cell infiltration was observed. RTX downregulated genes involved in immune cell recruitment and inflammatory aggregate organisation (e.g. CCR7, CCL19, CD52, and PDCD1) and gene signature-based analysis of 64 immune cell types highlighted how RTX preferentially blocked class-switched- and memory-B-cells infiltration in SGs at week 48. Pathway analyse confirmed the downregulation of leukocyte migration, $\mathrm{MHC}$ class II antigen presentation, and T-cell co-stimulation immunological pathways, such as the CD40 receptor complex pathway. The analysis of placebo SGs transcriptomic at week 48 showed a higher expression of genes linked to ectopic GC organisation, such as CXCL13, CCL19, LT $\beta$, in female compared to male subjects. Gender was confirmed as a key co-variate responsible for most of the variation in the PCA, together with the SG focus score and the foci area fraction.

Conclusion: Treatment with RTX showed beneficial effects on labial SG inflammatory infiltration in pSS, by downregulating genes involved in immune cell recruitment, activation and organisation in ectopic GCs. Class-switched-B-cells, memory-B-cells and FDC network development were primarily affected appearing to be responsible for the lack of progression in SG B cell infiltration in the RTX compared to the placebo arm in which clear worsening of SG immunopathology over 48 weeks was detected in female patients. Although a clear association with the clinical improvement in unstimulated salivary flow observed at week 48 in 
RTX-treated patients could not be established given the low number of patients consenting to 3 longitudinal biopsies it is conceivable that RTX is responsible for preserving exocrine function.

Acknowledgements: SJB receives a salary contribution from the NIHR Birmingham Biomedical Research Centre.

Disclosure of Interests: Elena Pontarini: None declared, Farzana Chowdhury: None declared, Elisabetta Sciacca: None declared, Sofia Grigoriadou: None declared, Felice Rivellese: None declared, Davide Lucchesi: None declared, Katriona Goldmann: None declared, Liliane Fossati-Jimack: None declared, Paul Emery: None declared, Wan Fai Ng: None declared, Nurhan Sutcliffe: None declared, Colin Everett: None declared, Catherine Fernandez: None declared, Anwar Tappuni: None declared, Myles Lewis: None declared, Costantino Pitzalis: None declared, Simon J. Bowman Consultant of: SJB In 2020 I have received consultancy fees from Novartis, Abbvie and Galapagos., Michele Bombardieri: None declared

DOI: 10.1136/annrheumdis-2021-eular.3960

\section{Spondyloarthritis - treatment}

\section{OP0137 TUMOR NECROSIS FACTOR INHIBITORS SHOW A DELAYED EFFECT ON RADIOGRAPHIC SACROILIITIS PROGRESSION IN PATIENTS WITH EARLY AXIAL SPONDYLOARTHRITIS: 10-YEAR RESULTS FROM THE GERMAN SPONDYLOARTHRITIS INCEPTION COHORT}

M. Torgutalp ${ }^{1}$, V. Rios Rodriguez ${ }^{1}$, M. Verba ${ }^{1}$, M. Protopopov ${ }^{1}$, F. Proft ${ }^{1}$, J. Rademacher ${ }^{1,2}$, H. Haibel ${ }^{1}$, M. Rudwaleit ${ }^{3}$, J. Sieper ${ }^{1}$, D. Poddubnyy ${ }^{1,4}$ ${ }^{1}$ Charité - Universitätsmedizin Berlin, Division of Gastroenterology, Infectious Diseases and Rheumatology, Berlin, Germany; ${ }^{2}$ Berlin Institute of Health,.., Berlin, Germany; ${ }^{3}$ Klinikum Bielefeld, Department of Internal Medicine and Rheumatology, Bielefeld, Germany; ${ }^{4}$ Deutsches RheumaForschungszentrum Berlin (DRFZ), Epidemiology Unit, Berlin, Germany

Background: Observational cohort studies have shown that there is low, but still detectable progression level in radiographic sacroiliitis, which might also have an impact on the function in patients with axial spondyloarthritis (axSpA). Recent data showed that tumor necrosis factor inhibitors (TNFi) might retard spinal progression when initiated earlier and taken longer in patients with axSpA. However, the question of whether they also have such an effect on radiographic progression in sacroiliac joints (SIJs) is still unclear.

Objectives: To investigate the longitudinal association between radiographic sacroiliitis progression and treatment with TNFi in patients with early axial SpA in a long-term inception cohort.

Methods: Based on the availability of at least two sets of SIJ radiographs, 301 patients (166 with nr-axSpA, symptom duration $\leq 5$ years and 135 with r-axSpA, symptom duration $\leq 10$ years) from the German Spondyloarthritis Inception Cohort (GESPIC) were included in this analysis. These patients contributed with a total of 7372 -year radiographic intervals. Two trained and calibrated central readers scored the radiographs according to the modified New York criteria. If both scored an image as definite radiographic sacroiliitis, the patient was classified as having $r$-axSpA. The sacroiliac sum score was calculated as a mean of both readers. The association between previous as well as current TNFi use and radiographic sacroiliitis progression, which was defined as the change in the sacroiliitis sum score over 2 years, was analysed using longitudinal generalized estimating equations (GEE) analysis.

Results: At baseline, 9 (3.0\%) patients were treated with a TNFi, and $87(28.9 \%)$ patients received at least one TNFi during the entire follow-up period. A total of 141 of the radiographic intervals were covered with TNFi of any duration, while 109 of them were covered with a TNFi of at least 12 months. While receiving $\geq 12$ months TNFi in the previous interval was associated with a lower progression of the sacroiliitis sum score compared to not receiving TNFi in the previous interval, this was not the case in patients who received TNFi $\geq 12$ months in the current 2-year interval (Figure 1). The significant association between TNF $\geq 12$ months in the previous interval and progression in the sacroiliitis sum score were confirmed in the adjusted multivariable longitudinal GEE analysis. In addition, a similar trend for the beneficial effects was observed in different models, which included other treatment definitions with TNFi in the previous 2-year interval (Table).

Conclusion: Treatment with TNFi was associated with retardation of radiographic sacroiliitis progression in patients with axSpA. This effect becomes evident between 2 and 4 years after treatment initiation.
Figure. A) Cumulative probability plot of the 2-year progression in the sacroilitis sum score, stratified by receiving at least 12 months TNFi in the previous and current 2-year radiographic intervals. B) The change in sacroilitis sum scores over two years in patients with axia spondyloarthritis treated vs non-treated with TNFi at least 12 months in the previous and current 2-year radiographic intervals.
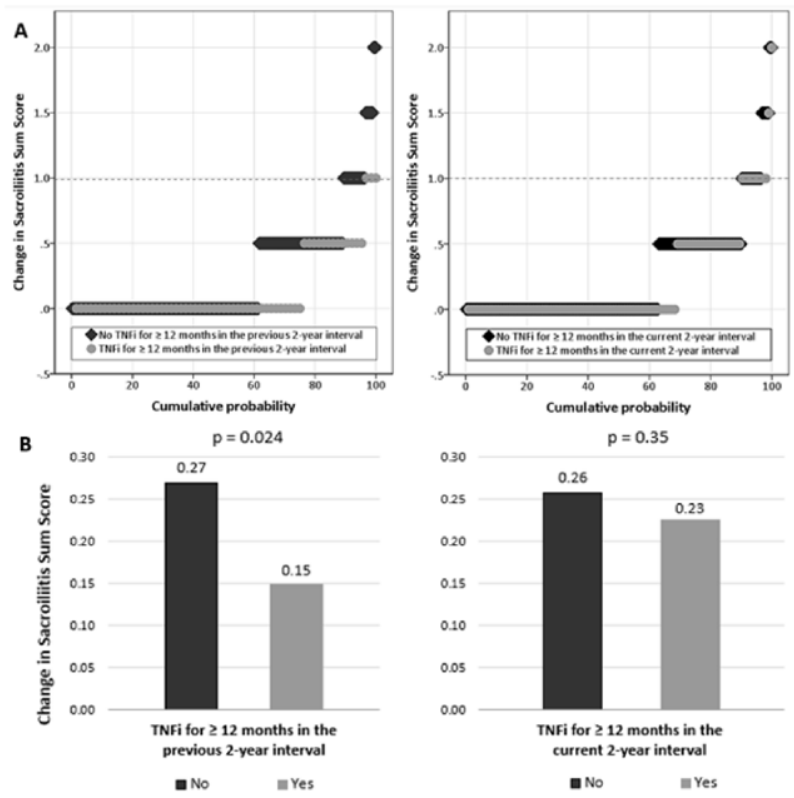

Table 1. The longitudinal GEE analysis of the association between progression in the sacroiliitis sum score and TNFi use.

\begin{tabular}{|c|c|c|}
\hline TNFi treatment definition & Reference & $\beta^{\star}(95 \% \mathrm{Cl})$ \\
\hline $\begin{array}{l}\text { TNFi for } \geq 12 \text { months in the } \\
\text { previous 2-year interval }\end{array}$ & $\begin{array}{l}\text { No TNFi for } \geq 12 \text { months in the } \\
\text { previous 2-year interval }\end{array}$ & $-0.09(-0.18,-0.003)$ \\
\hline $\begin{array}{l}\text { Any TNFi use in the previous } \\
2 \text {-year interval }\end{array}$ & $\begin{array}{l}\text { No TNFi use in the previous 2-year } \\
\text { interval }\end{array}$ & $-0.09(-0.17,0.002)$ \\
\hline $\begin{array}{l}\text { TNFi for } \geq 12 \text { months in the } \\
\text { current 2-year interval }\end{array}$ & $\begin{array}{l}\text { No TNFi for } \geq 12 \text { months in the } \\
\text { current 2-year interval }\end{array}$ & $-0.03(-0.11,0.06)$ \\
\hline $\begin{array}{l}\text { Any TNFi use in the current } \\
\text { 2-year interval }\end{array}$ & $\begin{array}{l}\text { No TNFi use in the current 2-year } \\
\text { interval }\end{array}$ & $0.05(-0.05,0.14)$ \\
\hline $\begin{array}{l}\text { TNFi for } \geq 12 \text { months in the } \\
\text { previous and } \geq 12 \text { months in } \\
\text { the current } 2 \text {-year interval }\end{array}$ & $\begin{array}{l}\text { No TNFi for } \geq 12 \text { months in the } \\
\text { previous and } \geq 12 \text { months in the } \\
\text { current } 2 \text {-year interval }\end{array}$ & $-0.08(-0.17,0.004)$ \\
\hline
\end{tabular}

* Parameter estimates from the multivariable models adjusted for sex, age at the beginning of the current 2-year interval, HLA-B27 positivity, symptom duration at the beginning of the current 2-year interval, time-averaged elevated CRP, time-averaged BASDAI, and time-averaged NSAID intake score in the current 2-year interval.

\section{References:}

Acknowledgements: GESPIC was initially supported by the BMBF. As a consequence of the funding reduction by BMBF according to schedule in 2005 and stopped in 2007, complementary financial support has been obtained also from Abbott, Amgen, Centocor, Schering-Plough, and Wyeth. Starting from 2010, the core GESPIC cohort was supported by AbbVie.

Disclosure of Interests: Murat Torgutalp: None declared, Valeria Rios Rodriguez: None declared, Maryna Verba: None declared, Mikhail Protopopov: None declared, Fabian Proft: None declared, Judith Rademacher: None declared, Hildrun Haibel: None declared, Martin Rudwaleit Consultant of: AbbVie, BMS Celgene, Janssen, Eli Lilly, MSD, Novartis, Pfizer, Roche, UCB Pharma, Joachim Sieper: None declared, Denis Poddubnyy Speakers bureau: AbbVie, Bristol-Myers Squibb, Lilly, MSD, Novartis, Pfizer, and UCB, Consultant of: AbbVie, Biocad, Gilead, GlaxoSmithKline, Eli Lilly, MSD, Novartis, Pfizer, Samsung Bioepis, and UCB, Grant/research support from: AbbVie, MSD, Novartis, and Pfizer DOI: 10.1136/annrheumdis-2021-eular.2926

\begin{tabular}{|l|l}
\hline OP0138 & FEASIBILITY OF PROGRESSIVE ANTI-TNF TAPERING \\
& IN AXIAL SPONDYLOARTHRITIS PATIENTS IN \\
& LOW DISEASE ACTIVITY: RESULTS FROM THE \\
& MULTICENTER NON-INFERIORITY PROSPECTIVE \\
& RANDOMIZED CONTROLLED TRIAL SPACING
\end{tabular}

C. Lukas ${ }^{1,2}$, A. Tournadre ${ }^{3}$, M. C. Picot ${ }^{4}$, E. Nogué ${ }^{4}$, E. Dernis ${ }^{5}$, P. Goupille ${ }^{6,7}$, B. Combe ${ }^{2}$, J. Morel' ${ }^{2}{ }^{1}$ University Montpellier, IDESP, Montpellier, France; 